\title{
Treatment of Raynaud's phenomenon with triiodothyronine corrects co-existent autonomic dysfunction: preliminary findings
}

\author{
R.F. Gledhill, P.H. Dessein ${ }^{1}$ and C.A. Van der Merwe ${ }^{2}$
}

Department of Internal Medicine, Division of Neurology and ${ }^{1}$ Department of Internal Medicine, University of Pretoria and Kalafong Hospital, and ${ }^{2}$ Institute of Biostatistics, Medical Research Council, Pretoria, South Africa

\begin{abstract}
Summary: Cardiovascular autonomic function was assessed in 9 subjects with Raynaud's phenomenon. The underlying diseases were systemic lupus erythematosus $(n=5)$, systemic sclerosis $(n=3)$ and rheumatoid arthritis $(n=1)$. Five standard non-invasive tests, 3 of heart rate and 2 of blood pressure, were employed. Compared with age and sex matched controls $(n=25)$, the number of values abnormal was 24 of $45(53 \%)$ overall and between one and 4 (median, 2) individually. Significant differences were present for 3 tests, two of heart rate and one of blood pressure.

The subjects were given triiodothyronine, 60 to $80 \mu \mathrm{g}$ per day, for vasospastic attacks. Autonomic function was reassessed between weeks 4 and 9 ( 9 subjects) and between weeks 12 and 18 (8 subjects) after introduction of triiodothyronine. Test results showed a considerable improvement. At the second reassessment, the number of values abnormal was now 5 of $40(12.5 \%)$ overall and nil $(n=4)$ or one $(n=4)$ individually. Significant differences remained for one heart rate test only. Adverse side effects to triiodothyronine occurred in a single subject and were readily controlled.

Evidence of somatic neuropathy was present electrophysiologically in all 9 subjects and clinically in 8 . Triiodothyronine may have corrected autonomic dysfunction by increasing blood flow to ischaemic peripheral nerves or by acting on the autonomic system more directly.

Further study of triiodothyronine in autonomic insufficiency appears merited.
\end{abstract}

\section{Introduction}

While developing a reference range for cardiovascular autonomic function tests, ${ }^{1,2}$ we observed that 3 individuals with Raynaud's disease (RD) ${ }^{3}$ had an exceptionally small rise in blood pressure (BP) in response to isometric exercise (Gledhill, R.F., Retief, J., unpublished data). This occasioned a study of subjects with Raynaud's phenomenon (RP). ${ }^{3}$ Five standard tests were employed and one or more values was abnormal in each of the 9 cases.

Despite an ever-increasing number of therapeutic agents available, many patients with RP continue to suffer disabling symptoms. Against that background, these same subjects subsequently were given triiodothyronine (T3) as remedial therapy for vasospastic attacks - a form of treatment recommended in standard texts, ${ }^{3}$ but apparently overlooked since Peacock ${ }^{4}$ published an encouraging report of its use 25 years previously.

Correspondence: Professor R.F. Gledhill, B.Sc., M.D., M.R.C.P., Faculty of Medicine, UAE University, P.O. Box 17666, Al Ain, United Arab Emirates.

Accepted: 4 November 1991
On account of the sustained remission that follow$\mathrm{ed}^{5}$ (an observation later affirmed in a formal trial of experimental design ${ }^{6}$ ) and having regard to the speculative role of the sympathetic system in the pathogenesis of such symptoms, ${ }^{7}$ autonomic tests were repeated. A significant trend towards normal values was found. Corrective effects on autonomic dysfunction to T3 constitutes, we believe, a quite novel observation.

\section{Methods}

\section{Study population}

The 9 subjects comprised the total RP population then attending our Rheumatic Diseases clinic. Each gave a history of episodic cold-induced biphasic or triphasic colour changes of the digits associated with pain or numbness. ${ }^{3}$ All were females, their ages ranging from 27 to 44 (median 41 ) years. Eight were black and one was white. Five had systemic lupus erythematosus, ${ }^{8} 3$ systemic 
sclerosis ${ }^{9}$ and one rheumatoid arthritis. ${ }^{10}$ The duration of these diseases ranged from 12 to 89 (median 52) months.

When studied, no subject was disabled or disclosed symptoms of autonomic insufficiency. ${ }^{11}$ None had diabetes mellitus, renal failure or signs of cardiovascular disease. Each was a non-smoker and denied alcohol consumption. Eight subjects had clinical evidence of peripheral neuropathy. Specifically, 5 had absent stretch reflexes and 3 impaired sense of pain, light touch or vibration distally in the lower extremities. In no case was medication being taken that reputedly impairs autonomic or peripheral somatic nerve function; ${ }^{2,11.12} 5$ subjects were receiving prednisone $(5$ to $60 \mathrm{mg} /$ day $), 3$ indomethacin $(15 \mathrm{mg} /$ day $)$ and 2 naproxen $(1 \mathrm{~g} /$ day $)$. Aside from reduction of prednisone in one subject (from 60 to $30 \mathrm{mg} /$ day), therapy remained unaltered throughout.

\section{Autonomic function tests}

The 5 tests were heart rate (HR) response to deep breathing, to Valsalva manoeuvre (Valsalva ratio) and to standing (30:15 ratio); and BP response to standing and to isometric exercise (sustained handgrip). ${ }^{1}$ All tests were conducted by the same two investigators using an electrocardiogram and arm sphygmomanometers of standard design. The laboratory temperature was maintained between $20^{\circ}$ and $26^{\circ} \mathrm{C}$. Reference data were obtained from 25 healthy volunteers matched for age and sex and studied concurrently (controls). Nine controls were tested twice to evaluate test-retest variability. Retesting took place after an interval of several days.

Post-treatment assessments of RP subjects were performed between weeks 4 and 9 (first reassessment) and between weeks 12 and 18 (second reassessment) after introduction of T3. One subject defaulted after the first reassessment.

\section{Nerve conduction studies}

Recordings were performed on all 9 RP subjects. The median (motor and sensory), peroneal (motor) and sural nerves, on one or other side, were sampled in every case using standard techniques. Sampling took place shortly after T3 had been introduced. Reference data were obtained from 44 healthy volunteers matched for age and sex and studied concurrently (controls). Seventeen of these persons were among the 25 who volunteered as controls for autonomic function tests.

\section{T3 administration}

T3 was introduced at $80 \mu \mathrm{g} / \mathrm{day} .{ }^{4}$ Eight subjects received this dosage throughout. In the one other, intermittent palpitations prompted a reduction to $60 \mu \mathrm{g}$ day. Adverse side effects were otherwise not experienced. Resting heart rate (HR) and BP were measured monthly. Compliance was verified by results of periodic thyroid function tests.

\section{Statistical methods}

Paired data were compared using the Wilcoxon matched pairs signed rank test. For unpaired data, the Mann-Whitney test was used with probability $(P)$ values being adjusted according to the Bonferroni principle. Changes relative to normality of test values following therapy with $\mathrm{T} 3$ were compared by the McNemar test for matched samples.

\section{Results}

\section{Autonomic function tests}

Individual RP subjects Test values were deemed abnormal if they fell below the lowest equivalent for controls. The number of tests abnormal individually was $1(n=1), 2(n=4), 3(n=2)$ or $4(n=2)$ pretreatment; nil $(n=1), 1(n=5), 2(n=2)$ or 3 $(n=1)$ at the first reassessment; and nil $(n=4)$ or 1 $(n=4)$ at the second reassessment. This tendency of values to normalize following treatment was present, to a varied degree, in every case.

Individual tests The number of values abnormal for each test pretreatment and at the first and the second reassessments was, respectively, 5, 3 and 1 for $H R$ response to deep breathing; 4,5 and 3 for Valsalva ratio; 6, 3 and nil for 30:15 ratio; 1,2 and nil for BP response to standing; and 8, 3 and 1 for $\mathrm{BP}$ response to handgrip. Corresponding aggregate proportions were $53 \%$ (24 of 45 ), $35 \%$ (16 of 45 ) and $12.5 \%$ ( 5 of 40$)$. Seventeen of the 24 abnormal pretreatment values had normalized at the first assessment while 7 of the 21 normal values had become abnormal; at the second reassessment, the respective figures were 17 and 1 . The trend toward normality of test values was significant at both reassessments (1st, $P=0.0495 ; 2$ nd, $P=0.0003$ ).

Groups The median resting HR of the RP subjects pretreatment was significantly faster than that of the controls ( 87 vs 72 beats $/ \mathrm{min}, P=0.007$ ).

Descriptive and inferential statistics for each test are shown in Table I. Intergroup comparisons revealed significant differences $(P<0.0167)$ for HR response to deep breathing, 30:15 ratio and BP response to handgrip pretreatment; for $H R$ response to deep breathing and 30:15 ratio at the first reassessment; and for 30:15 ratio alone at the second reassessment. Intragroup comparisons gave similar results. 
Table I Mean values (with standard error of the mean) for controls and for Raynaud's phenomenon subjects before (R1) and at the first (R2) and second (R3) reassessments after triiodothyronine therapy, with probability values for intergroup and intragroup comparisons

\begin{tabular}{|c|c|c|c|c|c|c|c|c|c|}
\hline \multirow[b]{2}{*}{ Test } & \multirow{2}{*}{$\begin{array}{c}\text { Controls } \\
(C) \\
(n=25)\end{array}$} & \multicolumn{3}{|c|}{ Raynaud subjects } & \multirow[b]{2}{*}{$C$ vs $R I^{*}$} & \multirow[b]{2}{*}{$C$ vs $R 2^{*}$} & \multirow[b]{2}{*}{$C$ vs $R 3^{\circ}$} & \multirow[b]{2}{*}{$R 1$ vs $R 2^{\dagger}$} & \multirow[b]{2}{*}{$R 1$ vs $R 3^{+}$} \\
\hline & & $\begin{array}{c}R I \\
(n=9)\end{array}$ & $\begin{array}{c}R 2 \\
(n=9)\end{array}$ & $\begin{array}{c}R 3 \\
(n=8)\end{array}$ & & & & & \\
\hline $\begin{array}{l}\text { HR on deep } \\
\text { breathing } \\
\text { (beats/min) }\end{array}$ & $21(1.4)$ & $9(2.1)$ & $12(2.5)$ & $20(3.2)$ & 0.0004 & 0.0123 & 0.6894 & 0.3743 & 0.0117 \\
\hline $\begin{array}{l}\text { Valsala } \\
\text { ratio }\end{array}$ & $\begin{array}{c}1.42 \\
(0.065)\end{array}$ & $\begin{array}{c}1.30 \\
(0.138)\end{array}$ & $\begin{array}{c}1.28 \\
(0.087)\end{array}$ & $\begin{array}{c}1.29 \\
(0.111)\end{array}$ & 0.1378 & 0.1183 & 0.1358 & 0.8658 & 0.6744 \\
\hline $30: 15$ ratio & $\begin{array}{c}1.36 \\
(0.051)\end{array}$ & $\begin{array}{c}1.06 \\
(0.034)\end{array}$ & $\begin{array}{c}1.15 \\
(0.041)\end{array}$ & $\begin{array}{c}1.13 \\
(0.016)\end{array}$ & 0.0003 & 0.0066 & 0.0040 & 0.2361 & 0.1235 \\
\hline $\begin{array}{l}\text { Systolic BP } \\
\text { on standing } \\
(\mathrm{mmHg})\end{array}$ & $-1(1.4)$ & $-6(2.2)$ & $-5(2.4)$ & $+2(2.5)$ & 0.1557 & 0.5035 & 0.2796 & 0.7223 & 0.1083 \\
\hline $\begin{array}{l}\text { Diastolic BP } \\
\text { on handgrip } \\
(\mathrm{mmHg})\end{array}$ & $33(1.5)$ & $11(2.3)$ & $27(3.9)$ & $32(3.0)$ & $<0.0001$ & 0.0382 & 0.6283 & 0.0077 & 0.0177 \\
\hline
\end{tabular}

'Values of $<0.0167$ for significance (Bonferroni principle applied); 'values of $<0.05$ for significance.

Values for the 9 controls tested twice did not differ significantly $(P>0.05)$ between the two assessments for any of the 5 tests.

\section{T3 administration}

Resting PR and BP did not change significantly $(P>0.05)$ when comparing pretreatment values with those at the first and the second reassessments.

\section{Nerve conduction studies}

All 9 RP subjects had evidence of somatic neuropathy at one $(n=7)$ or more $(n=2)$ of the sites sampled. The sural nerve was involved in 8 instances and the median sensory nerve, the median motor nerve and the peroneal nerve in one instance each. Abnormalities comprised nerve inexcitability (sural nerve only, $n=2)$, reduced amplitude of evoked action potential $(n=3)$ or mild $(<20 \%)$ slowing of conduction velocity $(n=6)$. Such findings are typically seen with axonal nerve degeneration.

\section{Discussion}

Autonomic dysfunction has been described in each of the underlying diseases that affected the RP subjects we studied. ${ }^{13-19}$ This, together with a frequency greater than suspected when sought systematically, ${ }^{14-19}$ may be sufficient explanation for its presence in every case. At the same time, we (Gledhill, R.F. and Retief, J., unpublished) and others ${ }^{17}$ have found cardiovascular autonomic tests to be abnormal in otherwise healthy persons with RD. Additional studies are required in both RP and RD before the question of pathogenesis in the present cases can be considered clearcut.

Test values taken as a whole showed a significant trend towards normality following therapy with T3. This general tendency was present in each of the 5 tests, attaining levels of significance for 2 of the 3 that previously differed. In the one other, moreover, all individual values now fell within the range of controls (data not shown). Improvement in autonomic function occurred to a greater or less degree in all 9 subjects. To the extent that readings did not differ in a similar number of controls on retesting, we believe the differences between pretreatment and post-treatment values were not due to spontaneous variation and that, in the absence of confounding variables, T3 was the factor responsible. The trial was non-experimental in design, however, and such inferences must necessarily remain tentative. We should nevertheless emphasize that values for change in $H R$ and $B P$ on standing, which are not effort dependent, improved to an equal extent, arguing against a placebo response. Also, the fact that the outcome of the study - with respect to autonomic function - was unanticipated would have largely neutralized any effects of observer bias.

Each of the RP subjects had a collagen vascular disease together with evidence of somatic peripheral neuropathy. Such neuropathies are thought to have a vascular pathogenesis ${ }^{20}$ and this must be 
reckoned with when considering mechanisms underlying the corrective effects of T3. Indeed, the dosages of $\mathrm{T} 3$ we used might be expected to increase tissue blood flow ${ }^{21}$ with consequent benefit to neural function. ${ }^{22}$ It was unfortunate that nerve conduction studies could not be repeated to assess whether such an eventuality did in fact materialize.

Augmentation of cardiovascular reflexes may have occurred by other, more direct means. Thus, T3 fulfills many criteria of an adrenergic neurotransmitter precursor. ${ }^{23}$ It also increases the function of central presynaptic alpha-2 adrenoreceptors, ${ }^{24}$ stimulation of which enhances the sensitivity of the baroreceptor reflex. ${ }^{25}$ Furthermore, thyroid hormones not only intensify the metabolic activity of both cardiac and smooth muscle ${ }^{26}$ but also have the attributes of a neuromodulator. ${ }^{27,28}$ Finally, experimental hyperthyroidism leads to profound changes in the metabolism of several biogenic amines with putative central neurotransmitter properties. ${ }^{29}$

\section{References}

1. Ewing, D.J. \& Clarke, B.F. Autonomic neuropathy: its diagnosis and prognosis. Clin Endocrinol Metab 1986, 15: 855-888.

2. Mcleod, J.G. \& Tuck, R.R. Disorders of the autonomic nervous system: Part 2. Investigation and treatment. Ann Neurol 1987, 21: 519-529.

3. Kontos, H.A. Vascular diseases of the limbs. In: Wijngaarden, J.B. \& Smith, L.H. (eds) Cecil Textbook of Medicine, 17th ed. W.B. Saunders, Philadephia, 1985, pp. 353-356.

4. Peacock, J.H. The treatment of primary Raynaud's disease of the upper limb. Lancet 1960, ii: 65-69.

5. Dessein, P.H. \& Gledhill, R.F. Treatment of Raynaud's phenomenon with large doses of triiodothyronine: a pilot study. Ann Rheum Dis 1987, 46: 944-945.

6. Dessein, P.H., Morrison, R.C., Lampereili, R.D. \& van der Merwe, C.A. Triiodothyronine treatment for Raynaud's phenomenon: a controlled trial. J Rheumatol 1990, 17: 1025- 1028.

7. Olsen, N., Petring, O.U. \& Rossing, N. Exaggerated postural vasoconstrictor reflex in Raynaud's phenomenon. Br Med J 1987, 1: 1186-1188.

8. Tan, E.M., Cohen, A.S., Fries, J.F. et al. The 1982 revised criteria for the classification of systemic lupus erythematosus. Arthritis Rheum 1982, 25: 1271-1277.

9. Subcommittee for Scleroderma Criteria of the American Rheumatism Association Diagnostic and Therapeutic Criteria Committee: Preliminary criteria for the classification of systemic sclerosis. Arthritis Rheum 1980, 23: 581-590.

10. Bennett, J.C., Rheumatoid arthritis. In: Wijngaarden, J.B. \& Smith, L.H. (eds) Cecil Textbook of Medicine, 17th ed. W.B. Saunders, Philadelphia, 1985, pp. 1911-1917.

11. McLeod, J.G. \& Tuck, R.R. Disorders of the autonomic nervous system: Part I. Pathophysiology and clinical features. Ann Neurol 1987, 21: 419-430.

12. Le Quesne, P.M. Neuropathy due to drugs. In: Dyck, P.J., Thomas, P.K., Lambert, E.H. \& Bunge, R. (eds) Peripheral Neuropathy, 2nd ed. W.B. Saunders, Philadelphia, 1984, pp. 2162-2179.
Whatever the mechanism(s), our findings suggest a formal, experimental trial of $\mathrm{T} 3$ in autonomic insufficiency is merited. Though symptoms of toxicity occurred in a single instance only and without untoward effect, it would seem judicious, given the potentially serious nature of $\mathrm{T} 3$-induced adverse reactions, the maintenance dosage in any future study should be somewhat lower than $80 \mu \mathrm{g}$ per day as utilized here. No loss of efficacy in the treatment of RP-associated vasospastic attacks was found, in fact, when dosages of $\leqslant 60 \mu \mathrm{g}$ per day were employed. ${ }^{6}$

\section{Acknowledgements}

We thank Dr Ewing for scientific advice, Sister A.M. Ratlhagane and $\mathrm{Mr}$ Y. Chetty for invaluable technical help and Professor P. Turner for appraising the manuscript.
13. McCombe, P.A., McCleod, J.G., Pollard, J.D., Guo, Y.-P. \& Ingall, T.J. Peripheral sensorimotor and autonomic neuropathy associated with systemic lupus erythematosus. Clinical, pathological and immunological features. Brain 1987, 110: 533-549.

14. Gledhill, R.F. \& Dessein, P.H. Autonomic neuropathy in systemic lupus erythematosus. J Neurol Neurosurg Psychiatry 1988, 51: $1238-1240$.

15. Sonnex, C., Paice, E. \& White, A.G. Autonomic neuropathy in systemic sclerosis: a case report and evaluation of six patients. Ann Rheum Dis 1986, 45: 957-960.

16. Dessein, P.H. \& Gledhill, R.F. More on autonomic neuropathy in systemic sclerosis. Ann Rheum Dis 1988, 47: 261-263.

17. Klimiuk, P.S., Taylor, L., Baker, R.D. \& Jayson, M.I.V. Autonomic neuropathy in systemic sclerosis. Ann Rheum Dis 1988, 47: 542-545.

18. Edmonds, M.E., Jones, T.C., Saunders, W.A. \& Sturrock, D. Autonomic neuropathy in rheumatoid arthritis. $\mathrm{Br} \mathrm{Med} \mathrm{J}$ 1979, ii: $173-175$.

19. Leden, I., Eriksson, A., Lilja, B., Sturfeldt, G. \& Sundkrist, G. Autonomic nerve function in rheumatoid arthritis of varying severity. Scand J Rheumatol 1983, 12: 166-170.

20. Conn, D.L. \& Dyck, P.J. Angiopathic neuropathy in connective tissue diseases. In: Dyck, P.J., Thomas, P.K., Lambert, E.H. \& Bung, R. (eds) Peripheral Neuropathy, 2nd ed. W.B. Saunders, Philadelphia, 1984, pp. 2027-2043.

21. Ingbar, S.H. The thyroid gland. In: Wilson, J.D. \& Foster, D.W. (eds.) Williams Textbook of Endocrinology, 7th ed. W.B. Saunders, Philadelphia, 1985, pp. 682-815.

22. Daube, J.R. \& Dyck, P.J. Neuropathy due to peripheral vascular diseases. In: Dyck, P.J., Thomas, P.K., Lambert, E.H. \& Bunge, R. (eds) Peripheral Neuropathy, 2nd ed. W.B. Saunders, Philadelphia, 1984, pp. 1458-1478.

23. Sterling, K. Thyroid hormone action at the cell level. $N$ Engl J Med 1979, 300: 173-177. 
24. Atterwill, C.K., Bunn, S.J., Atkinson, D.J., Smith, S.L. \& Heal, D.J. Effects of thyroid status on presynaptic alpha-2 adrenoreceptor function and beta-adrenoreceptor binding in the rat brain. $J$ Neural Transm 1984, 59: 43-55.

25. Van Zweiten, P.A. \& Timmermans, P.B.M.W.M. Cardiovascular alpha-2 receptors. J Mol Cell Cardiol 1983, 15: 717-733.

26. Barker, S.B. \& Klitgaard, H.M. Metabolism of tissues excised from thyroxine-injected rats. Am J Phyisol 1952, 170: 81 -86.

27. Smith, D.J. Immediate sensitisation of isolated swine arteries and their vasa vasorum to epinephrine, acetylcholine and histamine by thyroxine. Am J Physiol 1954, 177: 7-12.
28. Bilezikan, J.B. \& Loeb, J.N. The influence of hyperthryoidism and hypothyrodism on alpha- and beta-adrenergic receptor systems and adrenergic responsiveness. Endoc Rev 1983, 4: $378-388$.

29. Singhal, R.L., Rastogi, R.B. \& Hrdina, P.D. Brain biogenic amines and altered thyroid function. Life Sci 1975, 17: $1617-1626$. 